\title{
Standardization of experimental infection with Flavobacterium psychrophilum, the agent of rainbow trout Oncorhynchus mykiss fry syndrome
}

\author{
Céline Garcia ${ }^{1}$, Françoise Pozet ${ }^{1}$, Christian Michel $^{2, *}$ \\ ${ }^{1}$ Laboratoire Départemental d'Analyses du Jura, Boulevard Théodore Vernier, BP 376, 39016 Lons-le-Saunier Cedex, France \\ ${ }^{2}$ Institut National de la Recherche Agronomique (INRA), Unité de Virologie et Immunologie Moléculaires, \\ Centre de Recherches de Jouy-en-Josas, 78352 Jouy-en-Josas Cedex, France
}

\begin{abstract}
Rainbow trout fry syndrome (RTFS) is a septicaemic infection of young rainbow trout Oncorhynchus mykiss occurring at low temperatures and responsible for severe economic losses in European fish farming. The causative agent, Flavobacterium psychrophilum, is a gliding bacterium, and difficulties in culturing it have long been an impediment to investigations on pathogenesis and immunity. Successful attempts at experimentally inducing the disease have been reported, but no experimental model resulting in well-controlled and quantitatively reproducible effects has been described. Recent improvements in F. psychrophilum cultivation made it possible to produce bacterial suspensions with nearly constant viability and to complete challenge injections in rainbow trout fingerlings, using accurately adjusted infective doses. Parenteral injection resulted in significant mortality, which was higher when administered intramuscularly (IM) than intraperitoneally (IP). Lethal doses $50 \%$ lower than $10^{3}$ colony forming units were consistently obtained in trout weighing 3 to $5 \mathrm{~g}$, and the regular shape of the cumulative mortality curves appeared to lend itself to quantitative analyses. Bath experiments produced milder effects, although mortality ranging between 45 and $60 \%$ was obtained in $6 \mathrm{~g}$ trout when skin lesions or stressors were induced along with bacterial exposure. Temperature, salinity and the process of preserving isolates (at least over short periods of time) did not seem to be associated with the severity of infection. Nevertheless, infection trials performed at 2 different locations differing both in water quality and in the system of fish maintenance resulted in different mortalities. These findings notwithstanding, the proposed IM model appears easy to apply under standardized experimental conditions and should contribute to effective advances in the study of the disease.
\end{abstract}

KEY WORDS: Fish · Bacterial disease · Flavobacterium psychrophilum • Experimental infection · Standardization

Resale or republication not permitted without written consent of the publisher

\section{INTRODUCTION}

A significant part of the research conducted on infectious diseases is still dependent on animal experimentation (Zak \& Sande 1999). Although the concern with reducing the use of laboratory animals has led to the development of alternative and effective in vitro methods of investigation, such methods generally focus on well-identified mechanisms of pathogenicity. In many

*Corresponding author. E-mail: michel@biotec.jouy.inra.fr other cases, such as the very early steps in the exploration of a new agent, or when its virulent properties have not been clearly specified, experimental infection of laboratory animals remains a mandatory tool, and thoroughly standardized models of disease are required. Significant advances may be seriously hindered due to the lack of suitable models. This is illustrated by the recent history of the rainbow trout fry syndrome (RTFS). The causative agent, Flavobacterium psychrophilum, has been reported in different species of salmonids since 1948 (Borg 1960). Its simul- 
taneous occurrence in several Western European countries in the late 1980s (Lorenzen et al. 1997) was mainly limited to rainbow trout Oncorhynchus mykiss and expressed as a septicaemic clinical form which had rarely been reported before. This disease soon became a major source of concern in European rainbow trout hatcheries. For $10 \mathrm{yr}$, however, scientific investigations were mainly limited to field observations, detection methods, definition of fairly effective treatments and extensive study of taxonomical relationships. Michel et al. (1999) tentatively explained this apparent disinterest for pathogenic studies by the physiological requirements of $F$. psychrophilum and the difficulty of reproducing the disease under experimental conditions. At the same time, several authors tried to develop methods to improve the cultivation and preserve the viability of the bacterium (Daskalov et al. 1999, Michel et al. 1999).

In spite of the difficulty, some researchers addressed the problems of challenge and performed experiments through parenteral injection of, or water-borne exposure to, bacteria derived from virulent Flavobacterium psychrophilum cultures. Most of them reported successful but unreproducible results (Otis 1984, Holt 1987, Chua 1991, Lorenzen 1994, Rangdale 1995). In one case (Madsen \& Dalsgaard 1999), reproducibility of the results was claimed after subsequent, but independent infection trials performed with single isolates. Experimental RTFS thus appeared attainable, although not enough quantified data were produced in any of the cases to provide a valid comparison of mortality rates. Michel et al. (1999) described how to modify culture conditions of F. psychrophilum in order to harvest bacterial suspensions with consistent viability. The purpose of the present study was to use this method to prepare virulent inocula with reproducible characteristics, and to perform a series of infection trials in order to develop a standardized model of experimental disease.

\section{MATERIALS AND METHODS}

Origin and maintenance of trout. The choice of suitable fish for experimenting with Flavobacterium psychrophilum was a difficult one. The rainbow trout strain available in the experimental facilities of the INRA Research Center of Jouy-en-Josas (JJ; France) ('Synth' strain) could not be considered disease-free, because the bacterium had formerly been observed at the site and vertical transmission was suspected. After inquiries, a fish farm without history of RTFS was identified near Lons-le-Saunier (LS; Jura, France). This farm was located at the source of a river and maintained its own breeding stock of rainbow trout. The fish health status was tentatively checked on a sample of young fish, using the stress carrier detection method described for other fish bacteria (Bullock \& Stuckey 1975) with minor modifications: intraperitoneal injection of dexamethazone $0.01 \mathrm{mg}$, with temperature increase from 11 to $16^{\circ} \mathrm{C}$. Eventually, eggs were purchased from this farm ('Dal' strain), they were iodine disinfected, and the fry were hatched and reared in separate flowthrough aquariums in JJ. These fish were used throughout the study. In the first attempts, fish of the same stock which had been raised at the fish farm were acclimatized in the Departmental Veterinary Laboratory wet room, at LS. All infection trials used fish averaging 3 to $6 \mathrm{~g}$.

The facilities at LS consisted of 3001 troughs supplied with flow-through spring water of $11 \pm 1^{\circ} \mathrm{C}$, pH $7.05,6.8 \mathrm{mg} \mathrm{O}_{2} \mathrm{ml}^{-1}$ at a flow-rate of $31 \mathrm{~min}^{-1}$. In one of these troughs, 2 rows of 4 net cages (about 6.31 each) were arranged in series for experimental purpose. At JJ all experiments were conducted in 12 or $16 \mathrm{l}$ flowthrough aquariums supplied with dechlorinated and UV-sterilized tap water at 10 or $16^{\circ} \mathrm{C}$. Aeration was supplied using air-stones, and outlet water was collected in a special tank and treated with chlorine before being drained towards a water treatment plant. In all cases, fish were fed commercial dried pellets adapted to their size, at $3 \%$ (w/w).

Bacterial strains. Origin and maintenance: Six Flavobacterium psychrophilum strains isolated from clinical cases in France (Table 1) were used in the study. In order to preserve virulent properties, isolates were immediately lyophilized (Desolme \& Bernardet 1996) or frozen at $-80^{\circ} \mathrm{C}$ after isolation. In some cases, they were directly used after reisolation from the spleen of fish of the same origin, infected some days before.

Preparation of virulent bacteria: Bacterial strains were grown in enriched Anacker and Ordal (EAO) broth (Bernardet \& Kerouault 1989) supplemented with $5 \%$ horse serum. After $48 \mathrm{~h}$ incubation at $18^{\circ} \mathrm{C}$,
Table 1. Flavobacterium psychrophilum. Origin of the bacterial isolates used in the study (RTFS: rainbow trout fry syndrome; IPE: experimental facilities at the INRA research center of Jouy-en-Josas)

\begin{tabular}{|lll|}
\hline Strain number & Origin & Preservation \\
\hline JIP P02-99 & RTFS: spleen; IPE Jouy-en-Josas & $-80^{\circ} \mathrm{C}$ \\
JIP 30-98 & Healthy eel: kidney; Jura & $-80^{\circ} \mathrm{C}$ \\
JIP 02-97 & RTFS: spleen; Essonne & Lyophilization \\
JIP P29-98 & RTFS: spleen; IPE Jouy-en-Josas & Lyophilization \\
JIP 07-99 & RTFS: spleen; Aquitaine & Lyophilization \\
JIP 08-99 & RTFS: spleen; Aquitaine & Lyophilization \\
\hline
\end{tabular}


the bacteria were processed according to Michel et al. (1999). Erlenmeyer flasks containing the same medium supplemented with $0.02 \%$ of mineral solution of Lewin and Lounsberry (Dando \& Young 1990) were inoculated and incubated for 24 to $48 \mathrm{~h}$ in an orbital stirrer adjusted to $18^{\circ} \mathrm{C}$ and $80 \mathrm{rpm}$. The volume was generally $100 \mathrm{ml} \mathrm{flask}^{-1}$ but could be greater when preparing bath infections. Cell density, measured at $525 \mathrm{~nm}$ (Camspec M 330, Kontron, France), made it possible to estimate the number of viable bacteria present in the culture and to prepare suitable dilutions for subsequent infection. Serial 10-fold dilutions were performed in $0.9 \%$ saline, and a control count was made on solid EAO medium supplemented with horse serum, according to the droplet technique of Miles \& Misra (1938). Calculated doses were expressed as colony forming units (cfu) per fish or per ml of water.

Infection procedures. Lethal dose $50 \%\left(L D_{50}\right): \mathrm{LD}_{50}$ estimation was conducted on series of groups of 10 trout (sometimes 5) randomly distributed in individual cages (LS) or aquariums (JJ), and receiving 10-fold increasing doses of the virulent bacterial suspension.
After a period of acclimatization, fish were not fed the day before the experiment. They were anaesthetized with 2-phenoxyethanol $\left(0.3 \mathrm{ml} \mathrm{l}^{-1}\right)$ and injected intraperitoneally (IP) or intramuscularly (IM) with $0.05 \mathrm{ml} \mathrm{fish}{ }^{-1}$. Mock injections of saline were performed according to the same procedure in groups of control fish. Mortality was recorded for $30 \mathrm{~d}$, and all dying fish were submitted to bacteriological screening, including isolation and identification tests described by Bernardet \& Kerouault (1989).

Water-borne infection: Virulent bacteria (JIP P29-98 isolate) were produced as usual, except that higher quantities were needed and required 11 flasks. The concentration of bacteria for bath challenges was $10^{7} \mathrm{cfu} \mathrm{ml} \mathrm{m}^{-1}$. Groups of 60 fish divided into 3 groups were randomly distributed in the aquariums and were exposed to the bacteria for $1 \mathrm{~h}$, after reducing the water volume to 31 and turning off the water input, but keeping water aeration on.

Experimental schedules. Table 2 gives an overview of the different experimental conditions under which successive attempts were performed. The first 2 exper-

Table 2. Experimental schedules and resulting mortality rates of rainbow trout Oncorhynchus mykiss from infections with virulent Flavobacterium psychrophilum. nd: not determined. Number refers to individual aquariums or replicates. Injection doses encompass 10-fold dilutions, the highest dose being lower in some cases due to an insufficient number of bacteria. AOA: Anacker and Ordal agar; IM: intramuscular; IP: intraperitoneal; B: bath

\begin{tabular}{|c|c|c|c|c|c|c|c|c|c|}
\hline Expt & Strain & $\begin{array}{c}\text { Fish } \\
\text { Weight }(g)\end{array}$ & Number & Isolate & Source & Route & Dose & $\begin{array}{l}\text { Temperature } \\
\left({ }^{\circ} \mathrm{C}\right)\end{array}$ & Results \\
\hline \multicolumn{10}{|c|}{ Injections (dose: cfu; results: $\mathrm{LD}_{50}$ [cfu]) } \\
\hline \multirow[t]{2}{*}{1} & Dal & 3 & 10 & P02-99 & $-80^{\circ} \mathrm{C}$ & IM & $6-6.3 \times 10^{5}$ & 11 & nd \\
\hline & & & - & $30-98$ & - & IM & $8-7.7 \times 10^{5}$ & 11 & nd \\
\hline \multirow[t]{4}{*}{2} & Dal & 4.8 & 10 & P29-98 & Lyoph. Jan 1999 & $\mathrm{IM}$ & $10-9.2 \times 10^{5}$ & 11 & 246807 \\
\hline & & & - & - & - & IP & - & - & nd \\
\hline & & & 10 & $02-97$ & Lyoph. Feb 1997 & IM & $4-4.2 \times 10^{5}$ & 11 & 42000 \\
\hline & & & - & - & - & IP & - & - & nd \\
\hline \multirow[t]{2}{*}{3} & Dal & 3.1 & 10 & P29-98 & Lyoph. Jan 1999 & IM & $7-7.2 \times 10^{5}$ & 10 & 405 \\
\hline & Synth & 3 & - & - & - & - & - & - & 181 \\
\hline \multirow[t]{2}{*}{4} & Dal & 3.8 & 5 & P29-98 & Fish & IM & $17-1.7 \times 10^{6}$ & 10 & 403 \\
\hline & & & _- & - & - & - & - & 16 & 1700 \\
\hline \multirow[t]{3}{*}{5} & Dal & 4.3 & 10 & 08-99 & Lyoph. Mar 1999 & IM & $12-1.2 \times 10^{6}$ & 16 & 575 \\
\hline & & & - & $02-97$ & Lyoph. Feb 1997 & - & $2-2.3 \times 10^{5}$ & - & 73 \\
\hline & & & - & $07-99$ & Lyoph. Mar 1999 & - & $9-9.4 \times 10^{5}$ & - & 99 \\
\hline \multirow[t]{5}{*}{6} & Dal & 5.1 & 10 & P29-98 & 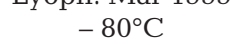 & IM & $20-2 \times 10^{6}$ & 10 & 65 \\
\hline & & & - & - & Lyoph. Jan 1999 & - & $15-1.5 \times 10^{6}$ & - & 429 \\
\hline & & & - & - & Lyoph. Aug 1999 & - & $16-1.6 \times 10^{6}$ & - & 33 \\
\hline & & & - & - & AOA & - & $16-1.6 \times 10^{6}$ & - & 268 \\
\hline & & & - & - & Fish & - & $18-1.8 \times 10^{6}$ & - & 137 \\
\hline \multicolumn{10}{|c|}{$\begin{array}{l}\text { Immersion (dose: } \text { cfu ml }^{-1} \text {; results: \% death) } \\
7\end{array}$} \\
\hline \multirow[t]{3}{*}{ Fresh water } & Dal & 5.8 & $20 \times 3$ & $07-99$ & Fish & B & $10.3 \times 10^{6}$ & 10 & 38.3 \\
\hline & & & - & & - & $\mathrm{B}+$ stress & - & - & 50 \\
\hline & & & - & & - & $\mathrm{B}+$ lesion & - & - & 55 \\
\hline \multirow[t]{3}{*}{$\mathrm{NaCl} 0.9 \%$} & Dal & 5.8 & $20 \times 3$ & 07-99 & - & B & - & 10 & 40 \\
\hline & & & - & & - & $B+$ stress & - & - & 46.7 \\
\hline & & & - & & - & $\mathrm{B}+$ lesion & - & - & 46.7 \\
\hline
\end{tabular}


iments, conducted in LS, were considered to be preliminary trials aimed mainly at selecting effective virulent strains and administration routes for further studies. In Expt 3, the susceptibility to infection of 2 independent fish strains (Synth and Dal) was compared. Comparisons of infections performed at different temperatures (Expt 4), of bacterial isolate virulence (Expt 5), and of several methods tested for preserving virulence (Expt 6) completed this part of the work.

The last experiment was designed to assess the effectiveness of water-borne challenge with virulent bacteria, together with several adjuvant treatments assumed to favour infections: a first group was merely exposed to virulent bacteria, a second one was stressed by being maintained for $1 \mathrm{~h}$ in a minimal volume of water, and a third was injured by adipose fin ablation. The same treatments were applied to another set of fish which were immersed in bacterial suspensions in the presence of $0.9 \% \mathrm{NaCl}$ instead of fresh water. A group of trout injected IM served as a positive control.

Data analysis. In all cases of parenteral injection, fish mortality was recorded for $30 \mathrm{~d}$ and cumulative mortality curves were plotted. Every moribund fish was examined for external lesions, and bacterial isolation was carried out from the spleen or the kidney on EAO plates. $\mathrm{LD}_{50}$ were calculated according to the experimental conditions, using the tables of Weil in Meynell \& Meynell (1970), which are based on moving averages and provide an easy estimation of the $95 \%$ confidence limits of the $\mathrm{LD}_{50}$. In water-borne infection experiments, mortality and survival on Day 35 were considered using chi-square tests in Microsoft Excel.

Table 3. Differences observed between expected (from optical density at $525 \mathrm{~nm}$ ) and controlled (plate enumeration) cfu concentrations of Flavobacterium psychrophilum cultures yielded for experimental infections. In Expt 6 P29-98 was used after freeze-drying (L1, L2), storage at $-80^{\circ} \mathrm{C}(\mathrm{C})$, storage at $4^{\circ} \mathrm{C}$ on culture medium (M), passage on fish (F)

\begin{tabular}{|c|c|c|c|c|}
\hline \multirow[t]{2}{*}{ Expt } & \multirow[t]{2}{*}{ Isolate } & \multicolumn{2}{|c|}{ Culture conc. $\left(10^{6} \mathrm{ml}^{-1}\right)$} & \multirow{2}{*}{$\begin{array}{c}\text { Difference } \\
(\%)\end{array}$} \\
\hline & & Expected & Measured & \\
\hline \multirow[t]{2}{*}{1} & P02-99 & 415 & 262 & -36 \\
\hline & $30-98$ & 76 & 59 & -22 \\
\hline \multirow[t]{2}{*}{2} & P29-98 & 460 & 423 & -8 \\
\hline & $02-97$ & 80 & 34 & -57 \\
\hline 3 & $29-97$ & 40 & 28 & -30 \\
\hline 4 & $29-97$ & 608 & 1020 & 67 \\
\hline \multirow[t]{3}{*}{5} & $08-99$ & 226 & 280 & 23 \\
\hline & $02-97$ & 34 & 10 & -70 \\
\hline & 07-99 & 113 & 103 & -8 \\
\hline \multirow[t]{5}{*}{6} & P29-98 (L1) & 586 & 574 & -2 \\
\hline & P29-98 (L2) & 246 & 190 & -22 \\
\hline & P29-98 (C) & 389 & 316 & -18 \\
\hline & P29-98 (M) & 84 & 146 & 73 \\
\hline & P29-98 (F) & 161 & 68 & -57 \\
\hline 7 & $07-99$ & 546 & 562 & -28 \\
\hline
\end{tabular}

\section{RESULTS}

Culture of the virulent bacteria did not give rise to any major problems, and although minor changes in production parameters (volume of culture, incubator) and experimental schedules could have led to some heterogeneity, the degree of variation in viable cell ratios remained within acceptable limits. As shown in Table 3, the differences between the theoretical and the real number of cfu per $\mathrm{ml}$ of culture rarely exceeded $50 \%$ (mean $35 \%$; maximum $73 \%$ ). These variations had no significant effect on reproducible virulence and infection rates.

At the LS facilities the first trial failed to produce any effect, but the second one using lyophilized trout isolates resulted in moderate and progressive mortality. A dose effect was clearly observed, and as shown with the most virulent of these isolates (Fig. 1), the IP administration route was not as effective as IM administration, although the appearance of the curves makes it seem to be effective. Similar conclusions had been reached in preliminary attempts, not reported here.

By applying the IM injection procedure, subsequent experiments resulted in increased severity of infection,
Legend:
$\triangle 4.2 \times 10^{5}$
$\checkmark 4.2 \times 10^{3}$
- $4.2 \times 10^{4}$
- $4.2 \times 10^{7}$
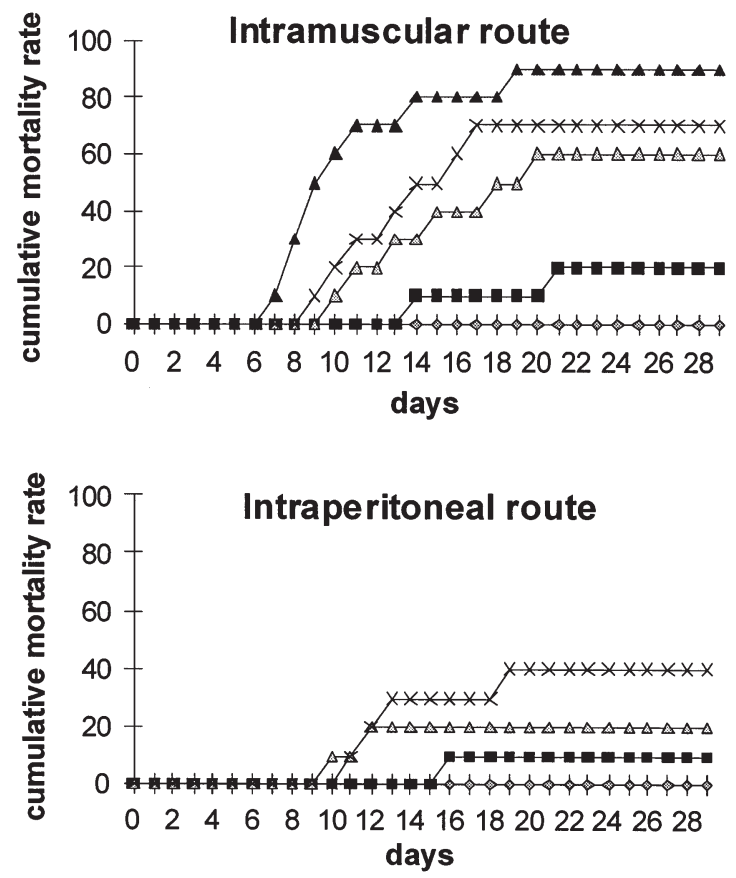

Fig. 1. Comparison of cumulative mortality in rainbow trout Oncorhynchus mykiss fry injected intramuscularly or intraperitoneally with 10-fold increasing doses (cfu) of Flavobacterium psychrophilum (strain JIP 02-97, trout 'Dal' at 10 fish group $^{-1}$, temperature $=10^{\circ} \mathrm{C}$; no fish died among non-infected controls) 


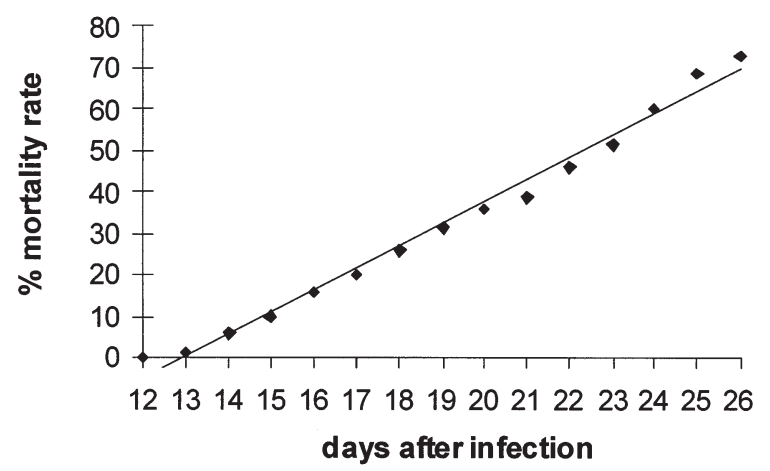

Fig. 2. Linear section of the cumulative mortality curve observed after intramuscular infection of rainbow trout Oncorhynchus mykiss fry with several Flavobacterium psychrophilum isolates at about 2 to $6 \mathrm{LD}_{50}$ (constructed after combination of Expts 3,4 and 6, conducted at $10^{\circ} \mathrm{C}$ )

and the significant rates of mortality were independent of the conditions in which the experiments were conducted (Table 2). $\mathrm{LD}_{50}$ ranged from 33 to $1700 \mathrm{cfu}$ fish $^{-1}$. Bacteria were recovered from all tested fish. Local necrosis of the skin and underlying muscle at the site of injection was observed in nearly all of the fish. Mortality generally evolved slowly and over a long period of time, depending on the dose. Fig. 2 illustrates an attempt at combining the data obtained from 10 comparable experimental groups, considering only the doses just above the $\mathrm{LD}_{50}$ (about 2 to 6 times the $\mathrm{LD}_{50}$ ).
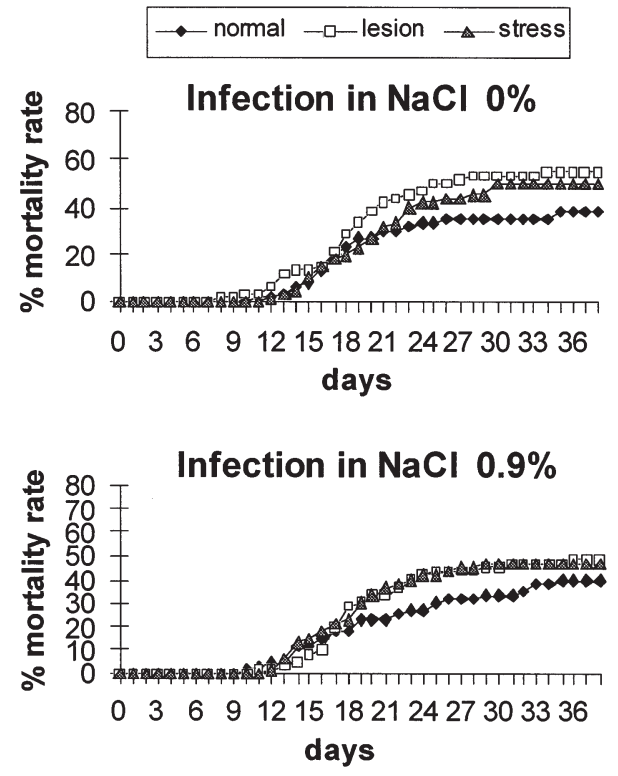

Fig. 3. Results of water-borne infection of young rainbow trout Oncorhynchus mykiss with the Flavobacterium psychrophilum JIP 07-99 strain, according to different treatments (challenge dose $=10.3 \times 10^{6} \mathrm{cfu} \mathrm{ml}^{-1}$; temperature $=10^{\circ} \mathrm{C}$; each curve results from groups divided into 3 triplicates; no fish died among non-infected controls)
It illustrates the regular and linear trends of cumulative mortality curves in typical assays, the course of the disease running from Day 12 to Day 26 after infection.

Bath exposure to virulent bacteria never resulted in infection rates as high as those found for injection. Maximum mortality rates ranged between 35 and $70 \%$ in individual aquariums. The mortality curves (Fig. 3) do not display the intra-group variability, which was higher when bath was conducted in fresh water, namely in the group submitted to external injury. Skin injury appeared to be a reliable way of aggravating the disease, although stress was as effective in the presence of $\mathrm{NaCl}$. Without lesion or stress, maximum mortality was $40 \%$ instead of $55 \%$. The difference, however, was not statistically significant. All $\chi^{2}$ tests were non-significant, with probabilities ranging between 0.17 (fresh water) and 0.62 (salt water). The kinetics of mortality, slightly longer compared to parenteral infection, did not differ greatly either. Once again, the bacterial strain could be reisolated from tested fish.

\section{DISCUSSION}

Experimental infection of young rainbow trout was induced on several occasions with significant mortality rates, using virulent Flavobacterium psychrophilum isolates from different origins. In agreement with other authors, we were able to demonstrate the feasibility of experimental disease results (Borg 1960, Otis 1984, Holt 1987, Chua 1991, Bruno 1992, Lorenzen 1994, Rangdale 1995), confirm their reproducibility (Madsen \& Dalsgaard 1999), and conclude that parenteral injection, particularly the IM route, is preferable. On this particular point, and in contrast to the opinion of Madsen \& Dalsgaard (1999), we are in agreement with Holt (1987), who considered IM and subcutaneous inoculations to be more effective than IP administration. It appears that no attempts were made in previous work to process and compare resulting data. In the present case, reference to $\mathrm{LD}_{50}$ was made possible by the standardization of bacterial culture production; this clearly made it possible to assess the effectiveness of the challenge and reproducibility of mortality levels in successive experiments. The computed $\mathrm{LD}_{50}$ values, often below $10^{3}$ and sometimes $10^{2} \mathrm{cfu} \mathrm{fish}^{-1}$, are probably the lowest ones reported using fish averaging 3 to 5 g. In comparison, Madsen \& Dalsgaard (1999) killed 60 to $70 \%$ of trout fry averaging 1 to $1.5 \mathrm{~g}$ with $10^{4} \mathrm{cfu}$ $\mathrm{fish}^{-1}$. Reproducibility is clearly illustrated by the successive experiments conducted with the strain JIP P2998. Using cultures prepared from bacteria which were freeze-dried at the same date or freshly reisolated from fish, independent experiments $(3,4,6)$ resulted in $\mathrm{LD}_{50}$ of $402,405,429 \mathrm{cfu} \mathrm{fish}^{-1}$, respectively. 
These results, together with the lesion induced at the inoculation point and the regular shape of dose-related mortality curves established after IM infection, made experimental flavobacteriosis suitable for standardization. Indeed, the resulting experimental model does not differ greatly from the model of furunculosis (Michel 1980). The main differences lie in water temperature and related observation times, which were adjusted to $30 \mathrm{~d}$ at $10^{\circ} \mathrm{C}$ for flavobacteriosis. In both models, IM injection proved to be the most appropriate for quantitative control of pathogenic effects, and injection of predictable infective doses resulting in low $\mathrm{LD}_{50}$ values could be achieved provided that culture conditions were strictly respected. In addition, it should be mentioned that the degree of correlation between the predicted and achieved infective doses was generally high, considering all of the experiments and isolates (Table 3). The difference never exceeded $73 \%$ (mean $35 \%$ ), thus confirming the reliability of the bacterial inocula and providing some degree of validation to the cultivation method proposed by Michel et al. (1999).

Throughout the series of infection trials it appeared that some of the experimental conditions were not critical in order to obtain successful results. Water temperature and the means of preserving the isolates did not seem to affect the infection trial to a significant degree, at least on a short-term basis (although Expt 6, aimed at comparing methods and supports for preservation, was designed to run for a longer time). However, in animal studies, a standardized model is not likely to work consistently in all situations. In fact, some other environmental or fish-related factors, which are not fully identified at the moment, could have an influence on the expected results, and this may explain the difficulties encountered in other experimental flavobacteriosis studies. Our disappointing initial attempts at LS illustrate the problem. The failure of the first experiment was probably due to uncontrolled preservation conditions of the isolates during their consignment to the experiment site, leading to a loss of virulence. Because infected trout exhibited relatively low mortality in Expt 2, another fish strain was included in the following attempt, at JJ, for fear that the Dal strain could prove naturally resistant. It turned out that this was not the case, and 2 possibilities remain to explain the observed differences between the results obtained at the 2 geographical locations. The first one may be related to different water quality characteristics: the Jura is an especially calcareous region, and the facilities are directly supplied with spring water, whereas JJ facilities depend exclusively on treated tap water. Another source of difference was the maintenance of the trout in preserved and controlled conditions in JJ, while fish of the same cohorts, kept in open fish farm conditions, were more likely to be exposed to natural aggressors and develop some degree of innate resistance. Madsen \& Dalsgaard (1999) also noticed different susceptibilities between fish originating from different farms.

After our own experience with other fish diseases, we suspected that water-borne challenges were only likely to have success using highly virulent isolates. They remained far below the values observed with parenteral infection, around 40 to $50 \%$ on average, but the fact that the trout fingerlings then averaged almost $6 \mathrm{~g}$ probably makes these results more promising than those previously published (Holt 1987, Rangdale 1995, Madsen \& Dalsgaard 1999). Our feeling is that the correct selection of virulent isolates on the basis of a wellmonitored IM model accounts for this. It is noteworthy that the different means classically used to increase the effectiveness of water-borne challenges in fish were not particularly advantageous, although the special role of stress, already discussed by Madsen \& Dasgaard (1999), is worth further investigation. Holt (1987) noticed the poor effect of skin surface alterations, so that the particular importance of bacterium penetration through skin lesions does not appear as easy to assess with Flavobacterium psychrophilum as with other bacteria responsible for fish septicaemia.

Bath challenges in water with low concentrations of added salt were aimed at protecting the bacteria from osmotic disturbance. In previous work (Michel et al. 1999) we noticed that Flavobacterium psychrophilum was highly susceptible to hypo-osmotic conditions, and Daskalov et al. (1999) seemed to support this observation, although no explanation was put forward. The latter authors reported significant improvement of the bacterium culture when different carbohydrates were added to the medium. As F. psychrophilum does not metabolize sugars (with the exception of chondroitin sulphate), osmotic protection could be an explanation. In our attempts, however, salt addition did not change the mortality rates. The only apparent outcome was a slight reduction of 'tank' effects and more homogeneous results among triplicates. In this case, some improvements could be expected from additional studies.

It is likely that bath infection techniques will never be standardized in the same manner as parenteral challenges, and this is not restricted to Flavobacterium psychrophilum. Even if bacterial concentrations could be adequately controlled, penetration into the host is too complex a mechanism to be quantitatively approached, since it is quite impossible to know the exact number of infective units that actually reach their target.

An opinion shared by many authors is that a disease model which could mimic a natural route of penetration is highly desirable in pathogenic or immunological studies, and that such a model could only be achieved through bath or cohabitation challenges (Bricknell 
1995, Nordmo 1997). Fortunately, the basis of this theory is not equally convincing in all situations. On the one hand, most of the literature about fish diseases emphasizes the special importance of handling procedures and ectoparasites in triggering bacterial infections and of the frequency of asymptomatic carrier fish. In many cases, the pathogen penetration results directly from microlesions impairing the skin integrity, or does not occur at all, and the first line of defence encountered by the pathogen presumably consists of systemic mechanisms. On the other hand, under certain circumstances with furunculosis, we have noted a good correlation between the results of bath and parenteral infections. The hypotheses that local immunity should act in dissociation from general defences and be an effective mechanism against bacterial proliferation in the case of external infection do not appear so definitively established in fish. It would at least require further investigation. Without disregarding the interest of local immunity, there are good reasons to consider that systemic models of infection remain highly valuable and still have much to offer in pathogenic studies.

Keeping this in mind, our results clearly showed that most of the difficulties encountered when standardizing experimental infection with Flavobacterium psychrophilum could be overcome as soon as the control of bacterial culture is ensured and reliable sources of fish are available. A significant degree of standardization was achieved in our facilities. As indicated, some factors influencing the severity of the infection would still have to be taken into account and be adjusted before the model is applied on a larger scale under varied conditions. Our work, however, should provide a useful basis for further elaboration of standardized and largely accepted methods in producing experimental flavobacteriosis.

Acknowledgements. This work was made possible by a grant from the Ecole Nationale Vétérinaire of Nantes. The authors express their thanks to Brigitte Kerouault, from the Unite de Virologie et Immunologie Moléculaires, Céline Piton, Eric Letellier and Gérard Fayemendi, from the experimental fish facilities of Jouy-en-Josas, whose help in preparing and looking after the experiments was invaluable for successful results.

\section{LITERATURE CITED}

Bernardet JF, Kerouault B (1989) Phenotypic and genomic studies of 'Cytophaga psychrophila' isolated from diseased rainbow trout (Oncorhynchus mykiss) in France. Appl Environ Microbiol 55:1796-1800

Editorial responsibility: David Bruno, Aberdeen, Scotland, UK
Borg AF (1960) Studies on myxobacteria associated with diseases in salmonid fishes. American Association for the Advancement of Science, Wildlife Disease, No. 8, Washington, DC

Bricknell IR (1995) A reliable method for the induction of experimental furunculosis. J Fish Dis 18:127-133

Bruno DW (1992) Cytophaga psychrophila (= 'Flexibacter psychrophilus') (Borg) histopathology associated with mortalities among farmed rainbow trout, Oncorhynchus mykiss (Walbaum) in the UK. Bull Eur Assoc Fish Pathol 12: 215-216

Bullock GL, Stuckey HM (1975) Aeromonas salmonicida: detection of asymptomatically infected trout. Prog Fish Cult 37:237-239

Chua FHC (1991) A study of the rainbow trout fry syndrome. MSc thesis, University of Stirling

Dando TR, Young JEP (1990) National collection of industrial and marine bacteria. Catalogue of strains: Flexibacter medium Ref. 281. NCIMB ldt, Aberdeen, p 177

Daskalov H, Austin DA, Austin B (1999) An improved growth medium for Flavobacterium psychrophilum. Lett Appl Microbiol 28:297-299

Desolme B, Bernardet JF (1996) Freeze-drying of Flavobacterium columnare, Flavobacterium psychrophilum, and Flexibacter maritimus. Dis Aquat Org 27:77-80

Holt RA (1987) Cytophaga psychrophila, the causative agent of bacterial cold-water disease in salmonid fishes. $\mathrm{PhD}$ thesis, Oregon State University, Corvallis

Lorenzen E (1994) Studies on Flexibacter psychrophilus in relation to rainbow trout fry syndrome (RTFS). PhD thesis, Royal Veterinary and Agricultural University, Copenhagen

Lorenzen E, Dalsgaard I, Bernardet JF (1997) Characterization of isolates of Flavobacterium psychrophilum associated with coldwater disease or rainbow trout fry syndrome I: phenotypic and genomic studies. Dis Aquat Org 31: 197-208

Madsen L, Dalsgaard I (1999) Reproducible methods for experimental infection with Flavobacterium psychrophilum in rainbow trout Oncorhynchus mykiss. Dis Aquat Org 36:169-176

Meynell GG, Meynell E (1970) Theory and practice in experimental bacteriology. Cambridge University Press, New York

Michel C (1980) A standardized model of experimental furunculosis in rainbow trout (Salmo gairdneri). Can J Fish Aquat Sci 37:746-750

Michel C, Antonio D, Hedrick RP (1999) Production of viable cultures of Flavobacterium psychrophilum: approach and control. Res Microbiol 150:351-358

Miles AA, Misra SS (1938) The estimation of the bacteriocidal power of the blood. J Hyg 38:732-749

Nordmo R (1997) Strengths and weaknesses of different challenge methods. Dev Biol Stand 90:303-309

Otis EJ (1984) Lesions of cold-water disease in steelhead trout (Salmo gairdneri): the role of Cytophaga psychrophila extracellular products. MSc thesis, University of Rhode Island, Kingston

Rangdale RE (1995) Studies on rainbow trout fry syndrome (RTFS). PhD thesis, University of Stirling

Zak O, Sande M (1999) Handbook of animal models of infection. Academic Press, London

Submitted: March 6, 2000; Accepted: July 4, 2000

Proofs received from author(s): September 4, 2000 